\title{
Dentifrice Reducing Levothyroxine Efficacy in Children
}

\author{
Samarendra Mahapatro ${ }^{1} \cdot$ Amit Kumar Satapathy ${ }^{1}$
}

Received: 9 February 2019 / Accepted: 14 May 2019 / Published online: 3 June 2019

(C) Dr. K C Chaudhuri Foundation 2019

To the Editor: Absorption of thyroxine supplement, used for the treatment of hypothyroidism, is interfered by several drugs and food. A two-years-old girl, a diagnosed case of congenital hypothyroidism $(\mathrm{CH})$ presented to us with elevated thyroid stimulating hormone (TSH) (38 mIU/l). She was started on L-thyroxine (Levothyroxine) at a dose $15 \mathrm{mcg} / \mathrm{kg} / \mathrm{d}$ elsewhere from day 5 of life after being diagnosed as $\mathrm{CH}$ on neonatal screening and was on regular follow-up since then. Previous TSH levels were found be within normal range on multiple occasions as per the medical records and she was taking L-thyroxine $50 \mathrm{mcg} / \mathrm{d}$ before visiting us. Growth and developmental milestones were appropriate for her age. She had weight of $12 \mathrm{~kg}(0$ to $+1 \mathrm{SD})$ and height of $84 \mathrm{~cm}(0$ to $+1 \mathrm{SD})$ at presentation. Compliance was good. Initially thyroxine dose was increased and compliance was ensured. Despite of hike in dose, repeat TSH after 1 mo remained to be elevated (42 mIU/l). There was no history suggestive of malabsorption syndrome and any other drug intake. On taking detailed history, parents revealed that the child had started brushing her teeth for last few months and she used to swallow the tooth paste while brushing. They used to give thyroxine immediately after brushing in empty stomach. Possibility of toothpaste hampering the absorption of thyroxine was considered. Hence, we advised to change the brushing pattern and introduced reward technique for the child and advised to give the medication in same dose 30-45 min after brushing. TSH level became normal (TSH $3.26 \mathrm{mIU} / \mathrm{l}$ ) subsequently and we were able to taper down the dose of thyroxine to $37.5 \mathrm{mcg} / \mathrm{d}$ on follow-up.

Drugs like ferrous sulfate, bile acid sequestrants and aluminum hydroxide decrease the absorption of levothyroxine [1-3]. In addition, high-fiber diets and other foods impair levothyroxine absorption too [4]. As per our knowledge, toothpaste interfering

Amit Kumar Satapathy

amitkumar.satapathy@yahoo.co.in

1 Department of Pediatrics, All India Institute of Medical Sciences, Bhubaneswar 761019, India with absorption of thyroxine has not been reported previously. Most of the common Indian toothpastes available in the market contain calcium carbonate or aluminum hydroxide as abrasive, sorbitol or glycerin as humectant and sodium lauryl sulfate as detergent. Flavourants are used to increase consumer acceptance too. A study of 20 patients receiving long-term levothyroxine replacement therapy indicates that calcium carbonate reduces $\mathrm{T}_{4}$ absorption and increases serum thyrotropin levels [5]. Uniqueness of our case lies in the fact that, though the parents were aware of taking medication in empty stomach but ignored the factor of tooth paste swallowing. Calcium containing toothpaste interfering with absorption of thyroxine is a less known fact. It is important for patients, parents and health care providers to have knowledge of various drugs and substances that interfere with $\mathrm{LT}_{4}$ absorption.

\section{Compliance with Ethical Standards}

Conflict of Interest None.

\section{References}

1. Campbell NRC, Hasinoff BB, Stalts H, et al. Ferrous sulfate reduces thyroxine efficacy in patients with hypothyroidism. Ann Intern Med. 1992;117:1010-3.

2. Northcutt RC, Stiel JN, Hollifield JW, Stant EG. The influence of cholestyramine on thyroxine absorption. JAMA. 1969;208:1857-61.

3. Sperber AD, Liel Y. Evidence for interference with the intestinal absorption of levothyroxine by aluminum hydroxide. Arch Intern Med. 1992;152:183-4.

4. Liel Y, Harman-Boehm I, Shany S. Evidence for a clinically important adverse effect of fiber-enriched diet on the bioavailability of levothyroxine in adult hypothyroid patients. J Clin Endocrinol Metab. 1996;81:857-9.

5. Singh N, Singh PN, Hershman JM. Effect of calcium carbonate on the absorption of levothyroxine. JAMA. 2000;283:2822-5.

Publisher's Note Springer Nature remains neutral with regard to jurisdictional claims in published maps and institutional affiliations. 